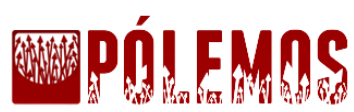

\section{A RELEVÂNCIA DA DIALÉTICA E DO PENSAMENTO DA DIFERENÇA NA CONSTITUIÇÃO DO PENSIERO DEBOLE VATTIMIANO}

\author{
Cláudia Dalla Rosa Soares \\ Mestranda na Universidade Federal de Ouro Preto - UFOP
}

\section{RESUMO}

No século XX, inaugura-se certa orientação filosófica como expressão de uma outra forma de se pensar, despojada das características autoritárias do pensamento fundacionista: o pensiero debole. Tal proposta filosófica, na qual se insere o filósofo Gianni Vattimo, segue uma orientação estéticohermenêutica como resposta aos problemas atuais, considerando as transformações ocorridas na sociedade contemporânea. Para Vattimo, a contemporaneidade é o momento em que se experiencia a Verdade e seu valor absoluto apenas como justificação ideológica da dominação e da violência. Tal acontecimento possibilita a vivência de "significações difusas" como potencialidade positiva de uma experiência "declinante" dos valores. Nesse sentido, o pensiero debole é uma filosofia que nasce como reconhecimento dos riscos do pensamento fundacionista, sendo, dessa forma, a reposta mais adequada à época do pluralismo da modernidade avançada. O objetivo deste artigo é expor a relevância do pensamento dialético e daquele da diferença na constituição do pensiero debole. Defende-se aqui que a relação existente entre pensiero debole, o pensamento dialético e o da diferença não se apresenta unicamente como uma "superação", ao contrário, define-se pela Verwindung, a saber, uma espécie de "ultrapassamento" como reconhecimento de vínculo que tem em si as características de aceitação e aprofundamento.

Palavras-chave: pensiero debole; dialética; diferença; Verwindung.

\begin{abstract}
In the twentieth century, the pensiero debole appears as a new philosophical orientation: an expression of a different way of thinking, without the authoritarian characteristics of foundationalist thought. The pensiero debole follows an aesthetic-hermeneutic orientation as a response to the current problems, considering the changes occurring in contemporary society. Gianni Vattimo is the main philosopher of the pensiero debole. The contemporary, to Vattimo, is the moment everybody experiences "the Truth" and its absolute value as an ideological justification of domination and violence. This event allows the experience of "diffuse meanings" as a potential positive experience. In this sense, pensiero debole is a philosophy that develops as a recognition of the risks of foundationalist thought. According to Vatimo, the pensiero debole is the most appropriate response to the post-modern society. The purpose of this article is to expose the relevance of dialectical thought and the difference thought in the constitution of pensiero debole. It is argued here that the relationship between pensiero debole, dialectics and the difference thinking is defined by a Verwindung, namely a kind of "torsion" as the recognition of a bond which carries the characteristics of acceptance and deepening.
\end{abstract}

Keywords: pensiero debole; dialectics; difference; Verwindung. 
O pensiero debole surge, na segunda metade do século XX, como resposta aos riscos do pensamento fundacionista: é uma maneira de interpretar não apenas a história da filosofia, mas principalmente as transformações histórico-epocais do presente. $\mathrm{O}$ pensiero debole defende ser capaz de compreender o presente e suas possibilidades sem nostalgias metafísicas, sendo a interpretação mais adequada à época do pluralismo pós-moderno. Tal proposta filosófica, na qual se insere o filósofo Gianni Vattimo (1936- ), segue uma orientação estético-hermenêutica como resposta aos problemas atuais, considerando as mudanças socioculturais ocorridas na contemporaneidade. Segundo Vattimo, hoje é praticamente impossível ser legitimamente fundamentalista ou monológico (OÑATE, 2008), pois, no momento presente, o "mito da unidade" (sistema, totalidade) funciona apenas como justificação ideológica da dominação. Valendo-se da crítica à qualquer determinação objetivista da Verdade, o pensiero debole nasceu como um pensamento capaz de combater todas as formas de violência metafísica, possuindo, dessa maneira, um valor ético e um caráter eminentemente político.

O objetivo deste artigo é expor a relevância do pensamento dialético e daquele da diferença na constituição do pensiero debole. Isso porque a relação existente entre o pensamento dialético e o da diferença não se apresenta unicamente como uma "superação", mas se define, ao contrário, pelo termo Verwindung: espécie de "ultrapassamento" como reconhecimento de vínculo que tem em si as características da aceitação e aprofundamento.

$\mathrm{Na}$ formulação do pensiero debole, é importante destacar a relevância do pensamento dialético, em particular, daquele heterodoxo dos filósofos de Frankfurt e do pensamento da diferença. A relação existente entre o pensamento dialético e o da diferença, na constituição do pensiero debole ${ }^{1}$, não se apresenta unicamente como uma "superação", mas se define, ao contrário, pelo termo Verwindung, ou seja, uma espécie de "ultrapassamento" como reconhecimento de vínculo que tem em si as características da aceitação e aprofundamento: algo diferente da Ueberwindung que caracteriza a superação dialética (VATTIMO, 1991). Por conseguinte, o pensiero debole não descuidou da dialética e do pensamento da diferença, pois

\footnotetext{
${ }^{1}$ Gianni Vattimo afirma que seus interesses religiosos e políticos o levaram a uma reflexão de tipo anti-moderno como uma maneira de se tentar uma crítica à modernidade ilustrada ou do comunismo marxista clássico. Por meio da leitura de Heidegger, Nietzsche, do existencialismo e da hermenêutica ele buscou uma terceira posição. Giovanni Giorgio destaca que "Vattimo parte de um problema romântico, aquele da relação entre finito e infinito, compreendido segundo a visão marxista, como condição de alienação da existência em relação ao seu sentido. (...) A existência contingente não é legitimada por meio do universal necessário, (...) essa permanece separada [scissa], alienada. (...) Marxismo e existencialismo, invertendo [rovesciando] o idealismo hegeliano, e evidenciando a questão do existente concreto, mesmo de pontos de vista diversos- do singular por Kierkegaard, da classe por Marx- repropõem a questão da superação de uma condição alienada, compreendida como cisão entre finito e infinito, entre existência e sentido" (GIORGIO, 2006, pp.13-4).
} 
constituiriam um passado no sentido do Gewesenes heideggeriano, ou seja, como envio e destino (VATTIMO, 1992a). Nesse sentido, o pensiero debole se apresenta como uma espécie de "remédio" ante as unilateralidades do pensamento dialético que prometia transformações ainda permeadas de autoritarismo, e da filosofia da diferença que imaginava uma origem na qual nunca se chega [in fondo vagheggiava a un'origine a cui non si arriva mai] (VATTIMO, 2006).

Quanto à herança da dialética no pensamento vattimiano, é relevante mencionar a importância de Hegel, Marx e Lukács, todavia, a dialética heterodoxa da Teoria Crítica dos filósofos de Frankfurt é a que merece maior destaque ${ }^{2}$. Isso porque os filósofos da dialética clássica, idealista ou marxista, defendiam ainda a totalidade como categoria essencial do dialética $^{3}$. Para Vattimo, a grande contribuição do pensamento dialético frankfurtiano consiste na compreensão de que a totalidade, que se apresentava como única possibilidade de acesso à verdade para a dialética tradicional, é, na realidade, uma noção dos dominadores ${ }^{4}$.

Todavia, Vattimo ressalta ainda a importância da crítica sartriana aos conceitos de totalidade e reapropriação. Sartre compreendia a dialética segundo as noções de totalidade e reapropriação, percorrendo assim a via dialética hegeliana: o verdadeiro é o inteiro, a formação autêntica do homem consiste no ponto de vista do todo. A crítica à ideologia é, não apenas, o desvelamento daquilo que está escondido, mas o esforço de recomposição de um ponto de vista não parcial, capaz de compreender a totalidade como tal. Ideologia não é apenas o pensamento falso que exprime de maneira mascarada (inconscientemente) o

\footnotetext{
${ }^{2}$ Nesse sentido, Giovanni Giorgio diz que a "relação que Vattimo mantém com a dialética hegeliano-marxista, particularmente com os filósofos do marxismo hetorodoxo do século XX (...) propriamente a articulação [proprio l'articolarsi] entre uma hermenêutica a serviço da dialética e uma hermenêutica livre da metafísica da dialética, parece oferecer uma fecunda chave de leitura do itinerário especulativo do pensamento de Vattimo" (GIORGIO, 2006, pp.10-1).

${ }^{3}$ Cf. VATTIMO, 2010, pp.17-8. Deve-se destacar que a noção de totalidade é característica do pensamento dialético, tanto hegeliano como marxiano. Daí Lukács afirmar: "não é o predomínio de motivos econômicos na explicação da história que distingue de maneira decisiva o marxismo da ciência burguesa, mas o ponto de vista da totalidade. A categoria da totalidade, o domínio universal e determinante do todo sobre as partes constituem a essência do método que Marx recebeu de Hegel e transformou de maneira original no fundamento de uma ciência inteiramente nova" (LUKÁCS, 2003, p.105). Lukács enfatiza que "o surgimento da inteligibilidade de um objeto a partir de sua função na totalidade determinada na qual ele funciona fazem com que a concepção dialética da totalidade seja a única a compreender a realidade como devir social" (Ibidem, p.85). Desse modo, segundo o materialismo-dialético,"a ciência proletária é revolucionária não somente pelo fato de contrapor à sociedade burguesa conteúdos revolucionários, mas em primeiro lugar, devido à essência revolucionária do seu método. O domínio da categoria da totalidade é o portador do princípio revolucionário na ciência" (Ibidem, pp.105-6).

${ }^{4}$ Vattimo escreve: "o pensamento dialético do século XX, tendo recebido [avendo recepito] as razões da inversão [rovesciamento] materialista do idealismo, se apresenta como pensamento da totalidade e (...) reapropriação, reivindicando como materialismo o resgate daquilo que a cultura dos dominadores excluiu. Mas, 'a parte maldita' [la parte maledeta] aquilo que foi excluído pela cultura dos dominantes não se deixa facilmente incorporar [ricompredere] em uma totalização: os excluídos fizeram experiência [hanno fato esperienza] de que a própria noção de totalidade é uma noção senhoril, [uma noção] dos dominadores" (VATTIMO, 1992a, p.17).
} 
verdadeiro, mas a ideologia mascara porque é pensamento parcial. Reconstrução da totalidade significa também reapropriação: somente se o panorama está completamente explicado, nós dispomos dele verdadeiramente (VATTIMO, 1992a, p.14).

Vattimo defende que o central em Sartre e na dialética do século XX é a consciência da problematicidade da relação entre totalidade e reapropriação. A Crítica da Razão dialética é uma crítica no sentido kantiano do termo, pois busca esclarecer em que condições é concretamente possível a constituição de um ponto de vista total, não ideológico. É sabido como Sartre resolve, mesmo que de modo não-definitivo, esse problema. Um saber totalreapropriado atua somente na consciência do grupo-em-fusão, o grupo revolucionário em ação, no qual teoria e prática tornam-se uma só, e a perspectiva individual coincide plenamente com a de todos. Todavia, essa solução revela um grave problema: o risco de se cair no prático-inerte após o momento revolucionário (VATTIMO, 1992a).

Segundo Vattimo, o mais importante no desenvolvimento da obra sartriana é o fato de ela explicitar o caráter mitológico da solução lukasciana do problema da totalidade que atribuía, com Marx, a capacidade de uma visão totalizante do sentido da história ao proletariado expropriado, e garantia, leninisticamente, a confiança dessa visão totalizante identificando a consciência de classe com a vanguarda do proletariado- o partido e sua burocracia. Sartre perseguiu até o fim o problema de como alguém pode se transformar no espírito absoluto hegeliano e dessa maneira não poderia obter sucesso. Todavia, seu insucesso trouxe uma positiva aquisição para o pensamento: Sartre expõe como a relação entre o ideal de um saber total-reapropriado e a estrutura de domínio deveria ser superada. O retorno do prático-inerte, após o momento revolucionário significa que o saber totalizante-reapropriado não pode subsistir, a não ser como uma nova forma de propriedade (também e, sobretudo, no sentido linguístico da palavra: o domínio do próprio contra a metáfora). Essa experiência é, antes de qualquer coisa, uma demonstração da fragilidade e da insustentabilidade, que podem ser reveladas em âmbito teórico, do ideal de reapropriação (VATTIMO, 1992a).

Nesse sentido, a relevância de tais pensadores não consiste tanto no fato de eles terem repensado a dialética, incluindo as exigências da micrologia, mas por terem afirmado as exigências da micrologia em oposição à dialética da totalidade. É para Adorno e Benjamin que a ideia de totalidade revela toda sua violência e falsidade (AGOSTINI, 2000). Tais filósofos não seriam, com efeito, pensadores da dialética, mas da sua dissolução (VATTIMO, 1992a). Na constituição do pensiero debole vattimiano, pode-se destacar a relevância do 
pensamento de Adorno $^{5}$ em suas críticas à racionalidade ocidental (ou, segundo o termo cunhado por Adorno e Horkheimer, racionalidade instrumental ${ }^{6}$ ) e ao pensamento sistemático moderno, por meio da proposta de uma dialética negativa ${ }^{7}$.

A reflexão filosófica adorniana principia com base na experiência dos acontecimentos nos campos de concentração de Auschwitz compreendidos como lugar emblemático da crise da razão ocidental (GIORGIO, 2006). A dialética negativa relaciona a crise dos grandes sistemas filosóficos e do pensamento metafísico com sua trágica paródia representada por Auschwitz e pelo mundo da administração total (VATTIMO, 2007). A experiência do nazismo revela o êxito extremo daquilo que Adorno chama de "destruição do não-idêntico". O desprezo do pensamento metafísico pelo transitório, pelo individual em sua especificidade e singularidade, "prepara" o extermínio de grandes massas de seres humanos em nome de uma teoria e por causa da subserviência à racionalização da existência, como pôde-se experienciar na sociedade administrada do mundo tecnologicamente avançado (VATTIMO, 2007). Em tal contexto histórico-social, torna-se explícita "a violência de qualquer racionalismo que implique a posse da verdade compreendida, seja como forma ideal, [seja] como sistema do real" (GIORGIO, 2006, p.152) ${ }^{8}$.

É por meio de sua "realização" (tanto no plano dos princípios quanto nos dos fatos, na organização da sociedade industrial, que começa, com efeito, a se desenhar maciçamente, por volta da Primeira Guerra Mundial), que o pensamento metafísico se revela como um pensamento da violência (VATTIMO, 2007). Se a tese de que o "verdadeiro é o todo" foi válida para Hegel, na contemporaneidade, quando tal racionalidade se realiza como uma paródia, no mundo da administração total, o todo torna-se falso ${ }^{9}$. Por isso, "a metafísica

\footnotetext{
${ }^{5}$ É relevante mencionar que Vattimo, no livro As aventuras da diferença, afirma que Adorno permanece "um termo de referência, pelo menos implícito, que acompanha o desenvolvimento destes ensaios" (VATTIMO, 1980, p.13) É interessante destacar ainda que, em 1959, logo após sua láurea (Il conceto di fare in Aristotele) Vattimo tencionava estudar Adorno. Procura Pareyson e diz "vorrei studiare Adorno". Todavia, Pareyson era bastante hostil aos intelectuais de esquerda que liam Adorno, o incentiva a estudar Nietzsche: "Ma che Adorno, leggi qualcosa di più atuale, studia Nietzsche". Assim Vattimo inicia seus estudos sobre Nietzsche por meio da leitura da tradução francesa das Considerações inatuais, em particular Sobre a utilidade e o dano da história para a vida. (Cf.VATTIMO, 2006).

${ }_{7}^{6}$ Para aprofundamento cf. ADORNO; HORKHEIMER, 1991 e HORKHEIMER, 2002.

${ }^{7}$ Nesse sentido, Adorno afirma que "a expressão 'dialética negativa' subverte a tradição. (...) [Essa] gostaria de libertar a dialética (...) $[$ da] natureza afirmativa, sem perder nada em determinação. (...) Isso implica uma crítica tanto ao conceito de fundamento quanto ao primado do pensamento do conteúdo. (...) O procedimento não é fundamentado, mas justificado. (...) A dialética negativa (...) poderia ser chamada de anti-sistema. Com meios logicamente consistentes, ela se esforça por colocar no lugar do princípio de unidade e do domínio totalitário do conceito supra-ordenado, a ideia daquilo que estaria fora do encanto de tal unidade" (ADORNO, 2009, pp.7-8- grifo nosso).

8 "In questa prassi storica si mostra tutta la violenza di ogni racionalismo che impliche il possesso della verità, intesa sia come forma ideale che come sistema del reale".

9 Nesse sentido, "é do ponto de vista do vivente que, com Adorno, se deve dizer que o inteiro é o falso" (VATTIMO, 1992a, p.16).
} 
termina quando culmina na atual racionalização técnico-científica do mundo, que remove toda transcendência e a transforma em presença totalmente imanente" (VATTIMO, 2007, p. $410)^{10}$.

É preciso sair da lógica do sistema, levando em consideração aquilo que é heterogêneo, transitório e individual. Daí Adorno defender:

a filosofia tem seu interesse verdadeiro voltado para o âmbito em relação ao qual Hegel, em sintonia com a tradição, expressou o seu desinteresse: o âmbito do não-conceitual, do individual e do particular; aquilo que desde Platão foi alijado como perecível e insignificante e sobre o que Hegel colocou sob a etiqueta de pueril. (...) Para o conceito, o que se torna urgente é o que ele não alcança, o que é eliminado pelo seu mecanismo de abstração, o que deixa de ser um mero exemplar de conceitos. (ADORNO, 2005, p.15).

Não obstante a contribuição da reflexão adorniana no desenvolvimento do pensiero debole,

Vattimo reconhecerá, em tal filosofia, certas características metafísicas, uma vez que

Adorno parece defender que nós podemos separar a metafísica como promesse de bonheur, como referência utópica para uma autenticidade transcendendo o presente estado de coisas, do seu desdobramento em uma racionalidade totalizante e em violência. (VATTIMO, 2007, p.410) ${ }^{11}$.

Sua filosofia objetiva ainda a passagem da alienação para a conciliação entre existência e sentido ${ }^{12}$, ainda que pensada em um futuro utópico (GIORGIO, 2006) ${ }^{13}$, e

\footnotetext{
10"Metaphysics ends when it culminates in the actual techno-scientific rationalization of the world, which removes every transcendence and transforms it into totally immanent presence".

11 "Adorno seems to claim that we can separate metaphysics as the promesse de bonheur, as a utopian reference to an authenticity transcending the present state of affairs, from its unfolding in totalizing rationality and in violence".

${ }^{12}$ Vattimo enfatiza que "em uma perspectiva dialética, qualquer tensão entre ser e dever ser, entre mundo fatual e mundo inteligível, é expressão de uma fratura que deve ser reconciliada; a tensão é provisória e é excluída [va sopresa]. Na preocupação de suspender indefinidamente a conciliação [...] Adorno parece tornar-se consciente de que aquilo que constitui a violência da metafísica não é tanto o mecanismo de transcendência, a referência a uma outra ordem de realidade que desvaloriza e humilha o imediatamente dado, quanto o mecanismo de fundação, o processo que pretende chegar a esse 'outro' que prometeu se estabelecer, se resolver em sua presença exposta [dispiegata], na sua Energheia" (VATTIMO. Apud: GIORGIO, 2006, p. 158). Nesse sentido, Vattimo realiza ainda diversas críticas ao ideal estético adorniano compreendido como meio de restauração da identidade do sujeito em um mundo em que este é ameaçado pela massificação universal. Para aprofundamento, Cf. VATTIMO, 2007, pp. 409-13.

${ }^{13}$ Giovanni Giorgio destaca que "qualquer aspiração à adequação conciliativa entre coisa e significado, remeterá sempre à utopia. Nesse sentido, a filosofia não poderá mais arrogar-se à pretensão de apreender a totalidade do real" (GIORGIO, 2006, p.156). Tal interpretação parece ser corroborada pelo último aforismo da Minima Moralia, no qual Adorno afirma que "o conhecimento não tem outra luz além daquela que, a partir da redenção, dirige seus raios sobre o mundo (...) [e] produzir perspectivas nas quais o mundo analogamente se desloque, se estranhe, revelando suas fissuras e fendas, tal como um dia, indigente e deformado, aparecerá na luz messiânica. (...). Obter tais perspectivas (...) é a coisa mais simples de todas, porque a situação clama irrecusavelmente por esse conhecimento (...) mas é também impossível, porque pressupõe um ponto de vista afastado- ainda que só um pouquinho- do círculo mágico da existência, ao passo que todo conhecimento possível não só deve ser
} 
permanece permeada de nostalgias metafísicas ${ }^{14}$. Daí Vattimo concluir:

apesar da ênfase na micrologia e na aparência, a dialética negativa ainda concebe a tarefa do pensamento em relação a um telos que é sempre definido em termos de presença, suprassunção alcançada, completude do ser. Mas não é a presença manifesta do ser- como suprassunção alcançada nada menos do que autoridade, majestade e comando- o que constitui a violência da metafísica? (VATTIMO, 2007, p. 412) ${ }^{15}$.

Quanto à crítica à natureza violenta do pensamento da totalidade, deve-se reportar ainda à reflexão benjaminiana. Benjamin critica a historiografia moderna ${ }^{16}$, uma vez que a história, compreendida como um curso unitário, exclui aquilo que não produziu verdadeiros e vistosos feitos históricos [vere Wirkungen, effetti storici] (VATTIMO, 1992a). Quem administra $a$ história é a classe dominante (ou, em termos benjaminianos, os vencedores), pois conserva dela apenas o que se coaduna com sua imagem para legitimar seu poder $\left(\right.$ VATTIMO, 1991) ${ }^{17}$. Desse modo, a ideia de que exista qualquer coisa como $a$ história, é uma expressão da cultura dominante (VATTIMO, 1992a). Os vencidos, porém, não podem compreender a história dessa maneira uma vez que seus fatos e suas lutas são violentamente excluídos da memória coletiva.

Para Benjamin é o ódio provocado por tal exclusão, mais do que o desejo de assegurar um destino melhor para o futuro, o que move a decisão revolucionária ${ }^{18}$. A revolução almeja

extorquido do existente, de modo a chegar a ser obrigatório, mas se vê por isso mesmo marcado pela mesma deformação e pela indigência a que pretende se subtrair (...). Até mesmo sua própria impossibilidade tem que ser por ele compreendida, a bem da possibilidade. Mas diante da exigência que a ele se coloca, a própria pergunta pela realidade ou irrealidade da redenção é quase indiferente" (ADORNO, 1993, pp.215-216- grifo nosso).

${ }^{14}$ Nesse sentido, Susan Buck-Morss defende que "de fato, pode-se argumentar que sem nenhuma fé no desenvolvimento histórico, todo o impulso de seus esforços para negar o intellectual 'material' teria sido simples niilismo, uma posição cujas implicações políticas seriam o anarquismo. Não obstante, a linguagem de Adorno, frequentemente, era mais idealista, mais metafísica do que sua intenção" (BUCK-MORSS, 1977, p.50grifo nosso). Ainda nesse mesmo sentido, Giovanni Giorgio afirma que "o objetivo do movimento dialético, continua sendo pensado segundo os mecanismos clássicos da teologia, típica do pensamento fundacionista. (...) Assim, Adorno põe-se no horizonte aberto por Nietzsche e Heidegger, ao identificar metafísica e violência, mas permanece preso [legato] à dialética e à idéia de ser que essa implica, e isso o faz um pensador ainda prénietzschiano e pré-heideggeriano" (GIORGIO, 2006, pp.157-8).

15 "Regardless of the emphasis on micrology and appearance, the negative dialectics still conceives of the task of thought in relation to a telos that is always defined in terms of presence, of achieved sublation, of a 'fullness' of Being. But is not the unfolded presence of Being- as achieved sublation no less than authority, majesty and command- what constitutes the violence of metaphysics?"

${ }^{16}$ Nesse sentido, Benjamin sustenta: “A tradição dos oprimidos nos ensina que o 'estado de exceção' em que vivemos é na verdade a regra geral. Precisamos construir um conceito de história que corresponda a essa verdade. (...) $\mathrm{O}$ assombro com o fato de que os episódios que vivemos no século XX 'ainda' sejam possíveis, não é um assombro filosófico. Ele não gera nenhum conhecimento, a não ser o conhecimento de que a concepção de história da qual emana semelhante assombro é insustentável” ( BENJAMIN, 1996, pp.226).

${ }^{17}$ Para aprofundamento Cf. BENJAMIN, 2006.

${ }^{18}$ Benjamin defende: "o sujeito do conhecimento histórico é a própria classe combatente e oprimida. Em Marx, ela aparece como a última classe escravizada, como a classe vingadora que consuma a tarefa de libertação em nome das gerações dos derrotados. (...) [A social-democracia] preferiu atribuir à classe operária o papel de salvar 
uma redenção que vingue e que restitua a palavra àqueles que foram excluídos e esquecidos pela história linear dos vencedores ${ }^{19}$. Desse ponto de vista, a revolução deveria resgatar todo o passado, e isso constituiria o seu buon diritto, sua superioridade em relação à cultura dos dominadores (VATTIMO, 1992a). Todavia, observa Vattimo, a instância micrológica deve ceder diante do problema da reapropriação, pois não há nenhuma garantia acerca da dizibilidade da "part maudite", isto é, daquilo que foi excluído da cultura dos dominadores e nada assegura que o ineffetuale, no momento de sua realização, não se torne voz de domínio e imposição (AGOSTINI, 2000).

Nesse sentido, Vattimo defende que o passado não pode ser resgatado em sua totalidade, mas que

o resgate acontece apenas em uma perspectiva de construção alternativa ao historicismo burguês. (...) O buon diritto da revolução não é mais fundado na capacidade de redimir tudo aquilo que foi excluído, é (...) o direito de uma nova força que se exercita por meio de outros atos de exclusão (VATTIMO, 1992a, p.16) $)^{20}$.

A tese proposta por Vattimo é a de haver, no século XX, uma tendência dissolutiva que o pensamento dialético não pode mais controlar $^{21}$. Daí ser preciso reportar-se ao pensamento da diferença ${ }^{22}$ de Nietzsche e Heidegger ${ }^{23}$ : pensamento considerado herdeiro e

as gerações futuras. Com isso, ela a privou de suas melhores forças. A classe operária desaprendeu nessa escola tanto o ódio como o espírito de sacrifício. Porque um e outro se alimentam da imagem dos antepassados escravizados, e não dos descendentes liberados" (BENJAMIN, 1996, pp.228-9- grifo nosso).

${ }^{19}$ Nesse sentido, Benjamin afirma que "articular historicamente o passado não significa conhecê-lo "como ele de fato foi'. (...) Em cada época, é preciso arrancar a tradição ao conformismo, que quer apoderar-se dela. (...) $\mathrm{O}$ dom de despertar no passado centelhas de esperança é privilégio exclusivo do historiador convencido de que os mortos não estarão em segurança se o inimigo vencer. E esse inimigo não tem cessado de vencer. (...) Ora, os que num momento dado dominam são herdeiros de todos os que venceram antes. A empatia com os vencedores beneficia sempre, portanto, esses vencedores. (...) Por isso, na medida do possível, o materialista dialético (...) considera sua tarefa escovar a história a contrapelo" (BENJAMIN, 1996, pp.224-5-grifo nosso).

20 "il riscatto avviene solo in una prospettiva di costruzione alternativa a quella dello storicismo borghese (...). Il buon diritto della rivoluzione non è più fondato sulla sua capacità di ridemere tutto ciò che è stato escluso; é (...) il diritto di una nuova forza che si esercita attraverso altri atti di esclusione".

${ }^{21}$ Segundo Vattimo, tal tendência revela que o ponto de vista dialético é profundamente cúmplice da alienação que deveria combater: as idéias de totalidade e reapropriação são noções metafísicas ainda não criticadas. (Cf. VATTIMO, 1992a, pp.17-8). Franca Agostini argumenta que "é interessante ver como Vattimo deduz o enfraquecimento de ambos princípios [totalidade e reapropriação] a partir da falência do programa dialético" (AGOSTINI, 2000, p.29).

${ }^{22}$ Giovanni Giorgio destaca ser necessário precisar os diferentes significados que a noção de diferença assume no pensamento vattimiano: “de um lado essa é a noção fundamental da metafísica e da dialética pela alienação que essa traz consigo quando exprime a cisão entre existência e sentido. De outro (...) porque a hermenêutica ultrapassa a dialética e a metafísica no modo da Verwindung, a diferença não vem simplesmente abandonada, mas declinada 'debolemente' como dialogicidade diacrônica e sincrônica. Neste sentido, a hermenêutica é pensamento não metafisico da diferença. E (...) porque a hermenêutica permite uma conciliação, com toda a precariedade e provisoriedade, entre existência e sentido, é também o lugar de uma conciliação 'debole"" (GIORGIO, 2006, p.208).

${ }^{23} \mathrm{O}$ contexto de Nietzsche e Heidegger era o de uma explosão dos conflitos, assim não era mais possível se manter uma racionalidade 'universal' fundamentada (por uma crença filosófica e/ou religiosa) no valor da 
radicalizador das tendências dissolutivas da dialética (VATTIMO, 1991) ${ }^{24}$. Nesse sentido, Vattimo defende que

a diferença como des-tituição do caráter definitivo da presença é (...) essencial ao pensamento para que este se constitua como pensamento "crítico", contra qualquer tentação de conciliações dialécticas e, portanto, contra qualquer tentação de reter (...) o fim da alienação e a condição de autenticidade. A diferença como ruptura é, assim, uma resposta à questão do carácter crítico que deriva dos pensadores que viveram mais radicalmente a aventura da dialéctica (VATTIMO, 1980, pp.12-3)

No entender de Vattimo, Nietzsche e Heidegger transformaram de forma substancial a própria noção de pensamento, “depois deles, 'pensar' assume um significado diverso do de antes" ${ }^{25}$ (Ibidem, p.9). Em Nietzsche, isso se explicita por meio de sua "crítica radical à metafísica" (VATTIMO, 2007, p.402) ${ }^{26}$, uma vez que sua reflexão foi a primeira a anunciar que a necessidade de fundamentação, isto é, os conceitos regentes da metafísica, a ideia de uma totalidade do mundo, de um sentido unitário da história e de um sujeito auto-centrado, eventualmente, capaz de se apropriar (VATTIMO, 1992a), é forma de violência e meio de disciplinamento não mais necessários na contemporaneidade. Conforme Vattimo, foi a atenuação generalizada do peso que se impunha sobre a condição humana a tornar inútil e obsoleta a "hipótese extrema" de um Ser Supremo: fundamento e finalidade última do mundo. Dessa forma, o anúncio nietzschiano da "morte de Deus" contribuiu para o desenvolvimento do pensiero debole como pensamento não-metafísico.

Deus não é mais necessário, revela-se como uma mentira supérflua (mentira exatamente só enquanto supérflua) por causa das transformações que, na nossa existência individual e social, foram induzidas exatamente pela crença nele. (...) O Deus da metafísica foi necessário para que a humanidade organizasse uma vida social ordenada, segura e não exposta continuamente às ameaças da

unidade. Daí Vattimo afirmar que Heidegger e Nietzsche não 'descobriram’ que a metafísica e a sua crença na unidade do ser, do mundo e da razão era falsa. Eles, ao contrário, ouviram os 'sinais do tempo'.

${ }^{24}$ Nesse sentido, Vattimo destaca que: "é provável que a Verwindung, a declinação da diferença em pensiero debole, possa ser pensada apenas se assume também a herança da dialética" (VATTIMO, 1991, p.20). A filosofia heideggeriana tem um "discurso que, definitivamente, parece responder melhor às (...) exigências do pensamento dialético. Uma vez que assume plenamente a inversão [rovesciamento] da filosofia na práxis em que pensava Marx, mas que nele não pode afirmar-se completamente (...) devido à sobrevivência de uma visão cientificista e objetivistica da verdade". (VATTIMO, 2009, pp.12-3).

${ }^{25}$ Segundo Santiago Zabala, a "filosofia, depois da desconstrução nietzschiana e heideggriana dos valores ocidentais, deve ser uma'aventura da diferença', pensamento liberado da condenação ideológica platônica, para então não errar reduzindo tudo a um único princípio" (ZABALA, 2007, p.13).

${ }^{26}$ Vattimo destaca que Heidegger compreende Nietzsche como um pensador metafísico: "para Heidegger, Nietzsche é decerto um pensador metafísico para ser lido em função do problema do ser; mas também e fundamentalmente, o último pensador da história da metafísica, na qual esta história chega a seu termo. (...) Paradoxalmente, o que Heidegger não reconhece em Nietzsche, a ligação peculiar do pensamento do fim da metafísica com a poesia e a literatura, é, aliás, o que ele próprio pratica no seu filosofar, como um diálogo entre pensar e poetar" (VATTIMO, 1990, pp. 10-11). 
natureza (...) e das pulsões internas, domadas por uma moral sancionada religiosamente, mas hoje que esta obra de asseguramento está, ainda que relativamente, concluída, e vivemos em um mundo social formalmente ordenado, dispondo de uma ciência e de uma técnica que nos permitem estar no mundo sem o terror do homem primitivo, Deus aparece como uma hipótese muito distante, bárbara, excessiva (VATTIMO, 1989, pp.10-11) ${ }^{27}$.

Vattimo destaca que a "morte de Deus" não é a enunciação metafísica da sua inexistência, mas a impossibilidade de afirmar o negar sua existência. É simplesmente "a constatação de um acontecimento, graças ao qual o ser já não necessita de ser pensado como dotado de estruturas estáveis e, em definitivo, de fundamento" (VATTIMO, 1980, p.167). Dessa maneira, a "morte de Deus" significa a negação do valor da verdade e, consequentemente, o fim da violência que dominou nossa vida por tantos séculos.

Trata-se, com efeito, de assumir positivamente os êxitos niilistas da "morte de Deus", como libertação do mundo simbólico e da criatividade dionisíaca ${ }^{28}$ e superação do conflito entre verdadeiro e falso. Daí Nietzsche se "despedir do passado e anunciar uma condição de vida diversa" (GIORGIO, 2006, p.132), na qual "não há fatos, somente interpretações", sendo esta também uma interpretação, pois seria contraditório se tal interpretação se pretendesse como descrição objetiva (VATTIMO, 2000). Se a necessidade de fundamentação mostra-se "produzida e 'funcional' em vez de originária” (VATTIMO, 2007, p.402) seria contraditório que tal filosofia pretendesse rejeitar os "erros metafísicos" e afirmar-se como verdade, de acordo com os parâmetros metafísicos de pensamento. Assim,

também a exigência de desmascaramento, como exigência típica de separar a verdade da mentira, mostra-se infundada: não há mais um mundo "verdadeiro" em relação ao qual se possa declarar "falso" ou "errôneo" qualquer outro ${ }^{29}$, assim não há mais a exigência de desmascaramento (GIORGIO, 2006, p. 132)

\footnotetext{
27 “Dio non è più necessario. La complessità ermeneutica di tutto cio cosiste nel fatto che Dio non è piu necessário, si revela come uma menzogna superfula (menzogna appunto solo in quanto superfula) a causa delle trasformazioni che, nella nostra esistenza individuale e sociale, sono state indotte próprio dalla credenza in lui (...) il Dio della metafísica è stato necessario perchè l'umanità si organizzasse uma vita sociale ordinata, sicura e non sposta continuamente alle minace della natura (...) e delle pulsione interne, domate da una morale sancita religiosamente; ma oggi che questa opera di rassicurazione è, sai pure relativamente, compiuta, e viviamo in um mondo sociale formalmente ordinato disponendo di uma scienza e di una técnica che ci permettono di stare al mondo senza il terrore dell'uomo primitivo, Dio appare um'ipotesi troppo estrema, barbarica, eccessiva".

${ }^{28}$ Para Vattimo "se o dionisíaco é o fluxo da vida que devora as formas, a existência é concebida como um esforço, (...) destinado ao insucesso, de sobreviver, (...) esquecendo-se (...) da terrível realidade do passar e do perecer. Se, ao contrário, o dionisíaco é (...) uma força 'livremente poetante', também a luta pela existência (...) torna-se apenas um caso particular de um evento mais amplo, que é a (...) produção de aparências, de símbolos, de formas sempre novas (...). Esta duplicidade de significados, que é uma contradição fecunda do desenvolvimento, pode ser expressa dizendo que o problema (...) de libertar-se do dionisíaco, da fuga do caos no mundo das aparências (...) tende a se transformar naquele da libertação do dionisíaco, isto é, do livre exercício de uma força metaforizante, de uma vitalidade inventiva originaria que não se contenta de ter atingido um plano de (relativa) segurança e liberdade do medo" (VATTIMO, 2003, pp.28-9).

${ }^{29}$ Nas palavras de Nietzsche: "o 'mundo verdadeiro'- uma ideia que para nada mais serve, não obriga a nadaideia, tornada inútil, logo refutada: vamos eliminá-la! (...) Abolimos o mundo verdadeiro: que mundo restou? O
} 
Esse é o mundo do Übermensch ${ }^{31}$, onde é possível a construção de novos significados sem nostalgias metafísicas. Nesse sentido é relevante mencionar as críticas que Vattimo realiza a uma leitura dialética (ou seja, metafísica) do pensamento de Nietzsche; pois essa interpretação visaria ainda, mesmo que utopicamente a reconciliação ${ }^{32}$, e pensaria o

ultra-homem como o homem que se libertou pelas diferenças e pela multiplicidade da experiência (...) [e] logo depois este homem liberto ainda é imaginado a partir do modelo de sujeito que "retornou a si" através das errâncias veladamente reguladas pelo itinerário dialético, e que no fim operou a unidade entre evento e sentido, a "beleza" da Estética de Hegel, perfeita coincidência entre interior e exterior (...) a arte (...) é descrita por Nietzsche como o lugar do ocaso do sujeito, da dissolução da forma, da unidade e das hierarquias. É este modelo que demonstra a insustentabilidade de uma interpretação ainda dialéctica do super-homem e da vontade de poder (VATTIMO, 1980, pp.11-2).

A superioridade hermenêutica da orientação nietzschiana consiste então na capacidade de instituir mundos simbólicos (GIORGIO, 2006), isto é, de ser

um pensamento capaz de se abandonar (sem medos metafísicos, sem as atitudes de defesa que se exprimem na redução de tudo a um único princípio, na posse do qual nada pode acontecer) à multiplicidade das aparências libertas da condenação platônica, que faz delas cópias de um original transcendente, o qual imediatamente impõe hierarquias e asceses (VATTIMO, 1980, p.10).

Para se pensar ainda uma crítica no sentido não-metafísico à metafísica, é preciso se considerar à reflexão heideggeriana ${ }^{33}$ acerca da epocalidade do $\operatorname{ser}^{34}$, pois

aparente, talvez?... Não! Com o mundo verdadeiro abolimos também o mundo aparente!" (NIETZSCHE, 2006.p.32).

30 “anche l'esigenza di smascharamento, come típica esigenza metafísica di separare verità e menzogna, viene portata alla luce come infondata: non esisti più un mondo 'vero' rispetto al quale poter dichiarare 'falso' o 'erroneo' qualcos'altro, dunque non c'è più esigenza di smascheramento".

${ }^{31}$ Vattimo destaca que “o além-do-homem [oltre'uomo] é 'além' [oltre] também porque não tem mais necessidade de realizar aquele ideal de conciliação absoluta que, para o homem da tradição metafísica até Hegel e Marx, sempre pareceu a única meta digna de ser buscada. O ideal de reapropriação está ainda, reativamente, muito vinculado às condições de 'expropriação' ao qual, a visão 'platônica' dos valores, a separação entre ideal e real, etc. o homem ocidental foi obrigado [a se submeter]” (VATTIMO, 1992b, pp.19-20).

${ }^{32}$ Segundo Vattimo: “o pensamento da diferença reconhece que do ser não se pode ter nunca a 'apreensão' plena, somente (...) rememoração, (...) recordação. O ser pensado assim nos liberta, nos deixa livres da imposição das evidências e dos valores, de todas as 'plenitudes' sonhadas pela metafísica tradicional que sempre (...) justificaram autoritarismos de todo tipo. (...) A dialética, ao contrário, pensa ainda sempre em referência a una possível presença 'plena', final, totalizadora, do ser (...) e corre o risco (...) de não nos libertar (...) (as vicissitudes do socialismo real não me parecem 'acidentais' em relação a este significado da dialética marxista, ainda que não acredite que não se possam deduzir única e necessariamente dela)" (VATTIMO, 1992b, pp.22-3).

${ }^{33}$ Segundo Vattimo, a reflexão heideggeriana é de extraordinária importância uma vez que "só ela parece capaz de nos abrir autenticamente à experiência de uma modernidade avançada sem uma permanente, subentendida, referência a cânones metafísicos. Isso é visível, no caso da estética, precisamente na substancial incapacidade 
como já claramente tinha intuído Nietzsche, (...) Heidegger demonstra por termos ontológicos, a tradição de um pensamento "violento" que, ao privilegiar categorias unificadoras, soberanas, generalizantes, no culto da arché, manifesta uma insegurança e um pathos de base à que reage com um excesso de defesa (...). Todas as categorias metafísicas (...) são "enfraquecidas" ou despotenciadas (VATTIMO, 1980, p.13).

Daí as reflexões de Heidegger sobre o sentido do ser, não terem conduzido à descoberta de uma estrutura transcendental de tipo kantiano nem de uma totalidade dialética, mas à insustentabilidade [insostenibilità] de se pensar o ser por meio das categorias que a tradição metafísica sempre lhe atribuiu, a saber, eternidade, ousia, estabilidade na presença ${ }^{35}$. Heidegger pensa cada vez mais na direção de uma filosofia do "declínio", que compreende que o constitutivo do ser não é o impor-se, mas, ao contrário, o desvanecer-se (VATTIMO, 1980). Daí a relevância do pensamento heideggeriano na constituição do pensiero debole: a filosofia heideggeriana responde às exigências, não apenas teoréticas, da experiência moderna de sair de um horizonte de pensamento que se revela inimigo da liberdade e da historicidade do existir (VATTIMO, 1998).

\section{REFERÊNCIAS BIBLIOGRÁFICAS}

ADORNO, T. Minima moralia. Trad. br. Luiz Eduardo Bicca. São Paulo: Editora Atica, 1993.

2009.

Dialética Negativa. Trad. br. Marco Antonio Casanova. Rio de Janeiro: Jorge Zahar,

ADORNO, T; HORKHEIMER, M. Dialética do esclarecimento. Trad.br. Guido Antonio de Almeida. Rio de Janeiro: Zahar Editor, 1991.

ANTISERI, Dario. Le ragioni del pensiero debole. Roma: Edizione Borla, 1995.

BENJAMIN, W. Obras Escolhidas, I. São Paulo: Editora Brasiliense, 1996.

que esta revela em considerar como chance final, e não apenas como perversão de valores e essências autênticas, a experiência da cultura de massas" (VATTIMO, 1989, p.99).

${ }^{34}$ Se a descoberta da superfluidade da metafísica se limitar a substituir o ser revelado falso pela crítica por um ser "verdadeiro", esta corre o risco de recair novamente na metafísica. Tal risco pode ser evitado somente por meio da retomada do problema do ser iniciada por Heidegger (Cf. VATTIMO, 1992, p.18).

${ }^{35}$ Cf. VATTIMO, 1980, p.13. "Heidegger pensa a razão kantiana não mais como qualquer coisa de eterno e com ' $\mathrm{R}$ ' maiúsculo, mas como algo historicamente dado. (...) Nada se subtrai à historicidade, muito menos a filosofia, o pensamento. (...) Heidegger não é mais inteligente do que Kant, mas vêm 120 anos depois de Kant. E nesse intervalo de tempo nasceram a antropologia cultural, a psicologia em suma, ciências, saberes que tornam incerta a ideia de que a razão seja sempre a mesma em todas as épocas e em todos os homens" (VATTIMO, PATERLINI, 2006, pp.131-2-grifo nosso). 
BUCK-MORSS, Susan. The origin of negative dialetics: Theodor Adorno, Walter Benjamin and the Frankfurt Institute .New York: The Free Press, 1977.

CARCHIA, G.; FERRARIS, M. Interpretazione ed emancipazione. Studi in onore di Gianni Vattimo. Milano: Raffaello Cortina Editore, 1995.

CIURLIA, Sandro. Le ragioni forti del pensiero debole. Mimeo.

D’AGOSTINI, Franca. Dialettica, differenza, ermeneutica, nichilismo: le ragione forti del pensiero debole. In: VATTIMO, Gianni. Vocazione e responsabilità del filosofo. P. 11-44. Genova : il melangolo, 2000.

GIORGIO, G. Nichilismo ermeneutico e politica. Disponível em <http://serbal.pntic .mec.es/ cmunoz11/ giorgio54.pdf > Acesso em: 10 julho 2012.

GIORGIO, G. Il pensiero di Gianni Vattimo. La emancipazione dalla metafísica tra dialettica ed ermeneutica. Milano: FrancoAngeli, 2006.

HORKHEIMER, Max. Eclipse da Razão. Trad. br. Sebastião Uchoa Leite. São Paulo: Centauro, 2002.

LUKÁCS, Georg. História e Consciência de Classe: estudos sobre dialética marxista.[1923] Trad. br. Rodnei Nascimento. São Paulo: Martins Fontes, 2003

MATTIA, D. Gianni Vattimo: l'etica dell'interpretazione. Conoscere, vedere e interpretare il mondo attraverso l'ermeneutica contemporanea. Firenze: Firenze Atheneum, 2002.

MONACO, D. Gianni Vattimo: ontologia ermeneutica, cristianismo e postmodernità. Pisa: Edizione ETS, 2006.

NIETZSCHE, F. Crepúsculo dos ídolos, ou Como se filosofa com o martelo, tradução de Paulo César de Souza. São Paulo: Companhia das Letras, 2006.

OÑATE, Teresa. Il limite dell'interpretazione. L'ontologia ermeneutica nella postmodernità nichilista. In: CHIURAZZI, Gaetano. (a cura di) Pensare l'atualità, cambiare il mondo. Torino: Bruno Mondadori, 2008.

VATTIMO, Gianni. As aventuras da diferença. Tradução: José Eduardo Rodil. Lisboa: edições 70, 1980.

La società trasparente. Milano:Garnzanti,1989.

.Oltre l'interpretazione. Roma-Bari: Editori Laterza, 1989.

. et al. Filosofia al Presente. Milano: Garzanti, 1990.

Introdução à Nietzsche. Bacarena: Editorial Presença, 1990.

La fine della modernità. Milano:Garzanti,1991.

Dialettica, differenza e pensiero debole. In: ROVATTI, P.; VATTIMO, G. (a cura di) Il pensiero debole. Milano: Feltrinelli Editore, 1992a. 
Más allá del sujeto. . Traducción de Juan Carlos Gentile Vitale. Ediciones Paidós Ibérica S.A.: Barcellona, 1992b.

Diferir a metafísica In: $O$ que nos faz pensar. Tradução: Antônio Abranches. N.10. V. 2, p.151-159, 1994.

Introdução a Heidegger.Tradução: João Gama. Lisboa: Instituto Piaget, 1996. ‘

.Acreditar em acreditar. Tradução: Elsa Castro Neves. Rio de Janeiro: Relógio D’Água Editores, 1998.

I limiti della derealizzazione, 2000. Mimeo

A tentação do realismo. Tradução : Reginaldo di Piero. Rio de Janeiro : Lacerda ed. : Istituto di Cultura Italiana, 2001.

.Il soggetto e la maschera. Nietzsche e il problema della liberazione. Milano: Bompiani, 2003.

VATTIMO, Gianni; PATERLINI, P. Non essere dio : Una biografia a quattro mani. Arezzo : Alberti editore, 2006.

.La filosofia come ontologia dell'atualità. Intrivista biográfico-teorica, 2006. Mimeo.

.Metaphysics and violence. In: ZABALA, Santiago. (editor). Weakening philosophy: essays in honour of Gianni Vattimo. London: McGill-Queen's University Press, 2007.

La cultura del novecento. Caserta: Edizione Saletta dell'Uva, 2007.

.Dalla fenomenologia a un'ontologia dell'atualità. In: CHIURAZZI, G. (a cura di). Pensare l'atualità, cambiare il mondo. Torino: Bruno Mondadori, 2008.

.O que esta vivo e o que esta morto no pensamento frágil. In: Filosofia contemporânea: niilismo-política-estética. PECORARO, R.; ENGELMANN, J. (orgs). Rio de Janeiro: Ed. PUC-Rio; São Paulo: Loyola, 2008.

. Addio alla verità. Roma : Meltemi, 2009.

Press, 2010.

Art's claim to truth. Translated: Luca D'Isanto New York: Columbia University Introduzione all'estetica. Pisa: Edizioni ETS, 2010.

VATTIMO, Gianni; GIRARD, René. Cristianismo e relativismo. Verdade ou fé frágil?.Aparecida, SP: Editora Santuario, 2010;

VATTIMO, Gianni; GAMPER, Daniel. Addio alla verità. Ma quale? MicroMega, Roma, Maio. 2011.

ZABALA, S. (edited by). Weakining philosophy: essays in honour of Gianni Vattimo. London: McGill-Queen's University Press, 2007. 